Sandro Mancilla Troncoso, ss.cc.

Licenciado en Teología

Pontificia Universidad Católica de Chile

\title{
Interpretación y fe: una breve presentación de la hermenéutica teológica de Paul Ricoeur
}

Hace poco más de un año, en mayo de 2005, recibimos la noticia del fallecimiento del filósofo hermeneuta francés Paul Ricoeur, para muchos uno de los más brillantes pensadores del siglo XX. Su nombre volvió a resonar a raíz de otro fallecimiento: el del hermano Roger de Taizé. La amistad de ambos hermanos protestantes, fundada seguramente en la complicidad de la fe, puso en conjunción la fecundidad de la fe cristiana en dos de sus expresiones más importantes, la espiritualidad y la reflexión intelectual, conjunción que tiene en nuestro autor, al que dedicaremos estas líneas, una expresión muy elocuente para nuestros días.

¿Cómo concibió la fe Paul Ricoeur desde su pensamiento hermenéutico? ¿Qué relación tiene la filosofía hermenéutica con la experiencia de la fe bíblica?

Ricoeur no dedica ningún texto al tratamiento del tema de la fe en forma explícita, lo que complica la elaboración de un artículo como este, sin embargo, la lectura serena de algunos de sus escritos, especialmente los relacionados con la hermenéutica teológica, nos descubren un mundo que nos posibilita enriquecer nuestra experiencia de fe tan íntimamente relacionada con la palabra revelada en los textos bíblicos.

La hermenéutica es para Ricoeur una filosofía de la interpretación cuyo objeto fundamental es la palabra, palabra que es potencia, que tiene el poder de desplegar el ser nuevo que anuncia (cf. 1975a, 94). Para poder desplegar ese ser nuevo la palabra se sirve del sistema de signos que conforma el lenguaje. El lenguaje es la estructura que permanece independiente de quien habla, es una mediación, un vehículo que nos permite dirigirnos hacia la realidad. Sin embargo, para que el lenguaje alcance toda su riqueza necesita el acto del habla, si no permanece estructura, permanece simplemente como instrumento.

El lenguaje pretende representar lo real por medio de signos, lo que implica, a su vez, comprender los signos como una representación de lo real. La fenomenología reconoce en esta pretensión una intencionalidad propia de la conciencia que se dirige hacia algo, hacia la realidad; dicha intencionalidad se realiza a través del habla.

El momento del habla se divide, a su vez, en dos momentos. El primero consiste en decir algo, es el momento de la idealidad del lenguaje, de la expresión del sentido; la idealidad de este momento se funda en que el sentido de lo dicho no 
existe ni en el mundo ni en la conciencia, no tiene realidad en sí mismo. El segundo momento surge porque el hablar implica decir algo sobre algo, es el momento de la realidad, en que lo dicho toca la realidad. Es por ello que toda palabra o habla significante supone lo que Ricoeur llama los dos umbrales de significación: umbral de sentido (ideal) y umbral de referencia (real). El habla distingue y articula los dos umbrales de significación: el sentido y la referencia del discurso, el decir algo y hablar sobre algo.

En esta mediación del lenguaje utilizada por el habla, la palabra se transforma en frase, pues las palabras logran algo, expresan su potencia, solo cuando están en posición de frase; en la frase las palabras ya no permanecen como una simple diferencia dormida en un diccionario, sino que son parte del acto del habla. Cada vez que alguien habla se produce una combinación transitoria y pasajera (frase) de signos (lenguaje). La frase, como acontecimiento del lenguaje, se transforma así en el punto de apoyo, en el soporte del habla. A través del habla apunto a algo de la realidad (significación), me dirijo a alguien (comunicación) y al mismo tiempo manifiesto mi propia intención (expresión) lo que me constituye como sujeto hablante (cf. 1968a, 152-154).

Para Ricoeur este fenómeno del acto del habla tiene un sustento ontológico que lo libera del peligro de una concepción reductivista. El decir algo como intencionalidad de la conciencia debe surgir de un proceso existencial que, según Ricoeur, precede y envuelve al lenguaje y su paso al habla, a la palabra; he aquí el sentido más profundo de la función mediadora propia del lenguaje. Se trata de una mediación que nace desde la manifestación del ser que se abre a nuestra percepción; es el sentido de aquello que captamos lo que expresamos a través de la fuerza de la palabra que, como hemos dicho, se sirve de todo el instrumental disponible en el lenguaje. Ricoeur expresa esto hermosamente: "Hay una comprensión, de alguna manera prelingüística, a partir de la cual nos elevamos al discurso propiamente dicho, a la enunciación, pasando por el modo clave de la interpretación, que pertenece a la existencia como tal (...) De esta manera, el silencio concierne a una filosofía de la palabra, en la medida en que decir es en primer término estar en silencio delante del sentido (...) El silencio significa que nuestra primera relación con el lenguaje consiste en escuchar y no en hablar (...)

La palabra es la sede de una dialéctica entre aquello que se manifiesta y aquello que captamos; entre la apertura del ser y su captura operada por nosotros. Aquello que se manifiesta pasa por el estrangulamiento de la garganta humana, que es el acto de violencia del poeta o del pensador" (1968a, 157-158; cf. 1967, 134).

El discurso como acto del habla puede pasar a la escritura. Para Ricoeur este paso a la escritura no es simplemente la fijación material de la palabra viva, sino más bien el establecimiento de una relación específica con las cosas dichas. Al mismo tiempo el discurso, en su paso a la escritura, hace un proceso de exteriorización definido por la constitución de una obra, que consiste en poner en forma el discurso mediante géneros literarios tales como la narración, la ficción, el ensayo, etc. Este doble proceso abre al discurso a una nueva autonomía (cf. 1977b, 181-182).

Dicha autonomía dice relación con la independencia que el texto escrito alcanza con respecto al autor, a su contexto y a su destinatario primero. Ya no existe el cara a cara de los interlocutores que había en el discurso hablado, ni el mundo 
circundante que les era común. Sin embargo, persiste la estructura básica del discurso, es decir, en el texto escrito también alguien dice algo a alguien sobre algo.

En el texto escrito aparece algo nuevo, él refiere a un mundo que no está en el texto, sino desplegado ante él. Esto es lo que Ricoeur llama, siguiendo a Gadamer, "la cosa del texto" que es el objeto más propio de la hermenéutica (cf. 1977a, 103-104).

El texto proyecta ante él y para el lector un mundo-del-texto, como lugar de acogida y mediación; no se trata de la intención perdida del autor detrás del texto como pretendía la primitiva filosofía hermenéutica, sino del mundo del texto ante el texto.

De esta manera lo que se interpreta en un texto es un mundo propuesto por el mismo texto, un mundo en el que es posible habitar y en el que se pueden proyectar las posibilidades más propias (cf. 1974b, 43; 1975a, 66; 1975c, 108; 1975d, 119).

Para Ricoeur lo que hace la escritura es abolir las características demostrativas o denotativas que tiene el discurso oral facilitadas por la posibilidad de mostrar una realidad común a los interlocutores. Es precisamente esta abolición la que hace posible el fenómeno de la literatura en la que se puede eliminar toda referencia a la realidad; no obstante, esta falta de referencia a la realidad es solo aparente, pues lo que realiza la literatura de ficción y la poesía es la eliminación de una referencia que nuestro autor llama de primer orden. Al desaparecer la referencia de primer orden se posibilita la liberación de un segundo orden de referencia que se dirige no solo al mundo de los objetos manipulables, sino al nivel designado por Husserl con la expresión Lebenswelt y por Heidegger como ser-en-el-mundo.

Según Paul Ricoeur, "a través de la ficción y la poesía nuevas posibilidades de ser-en-el-mundo son abiertas en la realidad de cada día. La ficción y la poesía se proponen ser, pero no a través de la modalidad de lo dado, sino más bien a través de la modalidad de las posibilidades. Y de esta manera la realidad diaria es transformada por medio de lo que podríamos llamar las variaciones imaginativas que la literatura obra sobre lo real" $(1974 b, 43)$.

Tal es la fuerza que puede tener el mundo del texto cuando opera en la transformación del mundo y la existencia del lector.

La imaginación, en este punto, surge para Ricoeur como una forma de invención que tiene sus reglas, surge como el poder que permite dar forma a la experiencia humana y (re)describir la realidad (cf. 1981, 144). La imaginación, por un lado, es estructurante en cuanto opera en la producción de un texto poético; pero, por otro lado, es también desestructurante en cuanto abre nuevas posibilidades existenciales para los lectores de aquellos textos (cf. 1989, 311). Nuestra imaginación es el poder de abrirnos a esas nuevas posibilidades, a descubrir nuevas maneras de ser. La imaginación es aquella parte de nosotros que responde al texto en cuanto texto poético (cf. 1977b, 198; 1990, 226).

Es el lector, como personaje real, el que relaciona el mundo posible del texto con el mundo real. En la lectura se confrontan dos estrategias: la del autor que es de persuasión desde el narrador al lector, y la del lector que es de combate, de sospecha y de rechazo y que le permite mantener la distancia en la apropiación.

Desde esta perspectiva la función del texto poético es ayudar al lector a leer su propia vida, pues posee en sí un poder mimético que permite reelaborar el actuar 
humano. El texto poético realiza una imitación creadora de la realidad que a la vez inventa (innovación semántica) y descubre (función heurística), estas son las bases del poder de refiguración que tienen los textos en su constante producción de sentido y revelación del ser.

La fuerza del texto y del mundo que él despliega se manifiesta y alcanza su plenitud en el movimiento de interpretación al que el mismo texto da origen. Para Ricoeur la tarea de la interpretación consistirá, en este sentido, en someterse a lo que el texto dice, a lo que propone, y a lo que significa.

Un movimiento de interpretación que concibe tal independencia, suficiencia y objetividad del texto, necesita definir con claridad lo que se entiende por significado.

Ricoeur comparte la idea de que el texto lleva a cabo su significado solo en la apropiación personal, en la decisión histórica, pero para él esta apropiación es solo la etapa final de la comprensión, puesto que, de lo contrario, el lugar que ocupa el texto y su mundo en la hermenéutica ricoeuriana perdería fuerza si no se lo considera como parte fundamental y primera del proceso de interpretación. La objetividad de la interpretación depende del lugar que se le dé al texto y su mundo.

Nos dice Ricoeur: "Es la objetividad del texto, comprendido como contenido -portador de significado y exigencia de significado- la que comienza el movimiento existencial de apropiación (...) Por lo tanto, el momento semántico, el momento de significado objetivo, debe preceder al momento existencial, al momento de la decisión personal, en una hermenéutica interesada en hacer justicia tanto a la objetividad del significado como a la historicidad de la decisión personal (...) Más que ninguna otra disciplina que trate sobre 'signos', la exégesis requiere tal instrumento de pensamiento. Si no hay significado objetivo, entonces el texto ya no dice nada en absoluto; sin apropiación existencial, lo que el texto dice ya no es palabra viva. La tarea de una teoría de interpretación es combinar en un proceso único estos dos momentos de comprehensión" (1968b, 68-69; cf. 1975d, 117-120).

Frente al mundo del texto el lector es invitado a tomar una decisión personal, a hacer una apropiación existencial de ese mundo, decisión que lo lleva hacia una nueva comprensión, a una nueva refiguración de sí y de su mundo. Esa decisión pasa por el momento de la interpretación que no puede soslayar la dimensión objetiva del significado del texto, de lo contrario se corre el riesgo de realizar una apropiación arbitraria de la palabra viva y de la significación de la cual es portador dicho texto.

Ya podemos ir vislumbrando la riqueza que este planteamiento contiene si lo aplicamos al texto bíblico como texto poético.

Pero antes conviene decir que para Ricoeur la palabra y el texto no son las únicas mediaciones para comprender el actuar humano, hay todo un conjunto de mediaciones simbólicas que también son importantes y que obviamente se deben tener en cuenta al momento de la búsqueda de comprensión del fenómeno de la fe. Entre estas mediaciones sobresale el testimonio.

El testimonio reúne en sí dos elementos que lo hacen merecedor de una particular atención; por un lado, la fuerza simbólica de una vida que es significativa por sí misma, y, por otro, la fuerza de la palabra que atestigua en favor de aquella manifestación del Absoluto (o "afirmación originaria" en palabras de Ricoeur) de la cual se ha sido testigo en la historia. 
El testimonio desata un doble movimiento que reclama la necesaria interpretación para su comprensión. Se trata, en primer lugar, del llamado a la propia conciencia al desprendimiento de sí en la reflexión para posibilitar el encuentro con los signos que el Absoluto da de sí mismo. Dicho desprendimiento de la conciencia consiste en el abandono de todos los condicionamientos y seguridades, es decir, en el abandono de la pretensión de constituirse a sí misma, pues a diferencia de Descartes, para Ricoeur no es posible una autoconciencia inmediata.

En segundo lugar, se inicia un movimiento impulsado por lo que Ricoeur llama criteriología de lo divino, es decir, se abre la posibilidad de descubrir en el testimonio recibido los criterios para elegir al Dios verdadero y desenmascarar a los falsos ídolos. A partir de este segundo movimiento es que se puede afirmar que es el mismo Absoluto el que da los criterios para reconocer la autenticidad de su manifestación, puesto que el testimonio simplemente transparenta y transluce aquello que el Absoluto, gratuitamente, quiere dar a conocer de sí (cf. 1972, 147-148; 1977b, 192).

Es interesante lo que sucede al relacionar estos dos elementos tan importantes en el pensamiento hermenéutico de Paul Ricoeur: el texto, con toda la fuerza que él le da al mundo propio que es capaz de desplegar ante sí, y el testimonio, con su potencial hermenéutico que hemos mencionado. En ambos subyace una afirmación originaria absoluta.

En el caso del texto es esta manifestación originaria absoluta -que el autor ha captado en el silencio, en la escucha ante la apertura del ser- la que se expresa a través de la palabra y de la escritura, produciéndose la distanciación necesaria que posibilita su interpretación en distintos contextos histórico-culturales en los que el lector se encuentre, de aquí que la categoría "mundo del texto" sea necesariamente a-histórica o trans-histórica (cf. 1977b, 190). El texto tiene un mundo propio que, de alguna manera, permanece como testimonio a través de la historia de aquella manifestación que le ha dado origen. Si aplicamos esto a la Sagrada Escritura podemos decir que esta es "testimonio" de la revelación de Dios a los hombres a través de la historia.

El testimonio, por su parte, también surge desde una manifestación originaria que se plasma en signos que el Absoluto hace aparecer de sí mismo en la historia (desde esta perspectiva la categoría "testimonio" agrega a la categoría "mundo del texto" la dimensión histórica que esta no tiene). Entre estos signos resalta el del testigo que es aquel que expresa con su vida la experiencia de la manifestación del Absoluto. Desde una perspectiva creyente, se trata de una vida que habla de la presencia de Dios en la historia en medio de la comunidad humana.

El testimonio tiene su dimensión textual en la narración que realiza el testigo acerca de su experiencia, dicha narración siempre se lleva a cabo en el contexto del proceso de juicio al que es sometido todo testimonio en la necesidad de decidir entre el falso y el verdadero testigo.

Podemos decir, entonces, que las mediaciones ineludibles por las cuales es posible comprender el actuar humano: símbolos y textos, están presentes también en el proceso de la fe cristiana, ya sea por medio de la Escritura o por el Testimonio del creyente.

Entremos ahora, más claramente, en el texto bíblico. Para Ricoeur el lenguaje religioso o bíblico es una variedad del lenguaje poético, entendiendo la función 
poética "como el poder de hacer que la redescripción de la realidad corresponda con el poder de llevar las ficciones de la imaginación al habla" (1975b, 107), es decir, como el poder de recrear la realidad a través del texto. Sin embargo, para Ricoeur, el lenguaje religioso -a través de la hermenéutica- muestra su carácter específico hasta el punto de hacer aparecer la función poética como un medio de dicho lenguaje (cf. 1975b, 107). ¿En qué consiste este carácter específico?

En su paso por el lenguaje, la fe bíblica se sirvió de diversas formas de discurso como son la narración, la profecía, el himno, etc.

Este conjunto de discursos que componen el relato bíblico tiene como característica particular su referencia a Dios. Para Ricoeur el referente Dios en el texto bíblico es a la vez el coordinador de estos discursos y lo que indica el aspecto abierto y no acabado de ellos; según esto último estos discursos parciales permanecen abiertos apuntando constantemente a ese referente que los excede.

Al referirse a Dios se apunta a algo más que a un término filosófico, como sería incluso el término "ser". Para Ricoeur la palabra "Dios" dice más, pues presupone el contexto total constituido por el conjunto de los relatos, de las profecías, de las legislaciones, de los himnos, etc.

El conjunto de estos textos pretenden expresar aquello que permita una mejor comprensión de Dios, a través de su referencia a Él. Sin embargo, ya la sola comprensión de la palabra "Dios" implica el difícil desafío de profundizar el sentido que tiene esa palabra y que en el contexto de los relatos bíblicos conlleva una doble tarea para el hermeneuta, que coincide con la doble función del referente Dios: reunir todos los significados surgidos de los discursos parciales, y abrir un horizonte que escapa al discurso ya cerrado o completo.

Para Ricoeur, lo mismo se puede decir de la palabra "Cristo", pues a la doble función de la palabra "Dios", aquella "agrega la capacidad de encarnar todos los significados religiosos en un símbolo fundamental: el de un amor sacrificial, de un amor más fuerte que la muerte. La función de la predicación de la Cruz y de la Resurrección es dar a la palabra 'Dios' una densidad que la palabra 'ser' no encierra. En su significado está contenida la noción de su relación benevolente con nosotros y de nuestra relación con él como últimamente concernidos y plenamente agradecidos" (1975d, 119-120; cf. 1968a, 160-161; 1974b, 45-46; 1975a, 68-69).

El carácter específico, por tanto, se puede explicar de la siguiente manera: El texto bíblico como texto poético tiene un referente, el referente Dios. Para expresar a Dios el lenguaje religioso utiliza lo que podemos llamar "modelos" o imágenes como son por ejemplo las de monarca, juez, esposo, etc. y que se expresan a través de distintas formas literarias como son los relatos, las profecías, las leyes, etc. Estos modelos, a su vez, funcionan por medio de la ley o dinámica de la analogía, y de cierta forma son incapaces de nombrar a Dios, pues tienen una tendencia a la representación antropomórfica que se acerca peligrosamente a la representación idolátrica.

Hasta aquí podríamos decir que la diferencia con otros textos poéticos permanece difusa, pues dicha diferencia estaría dada solamente por la referencia a Dios. Sin embargo, Ricoeur plantea que estos "modelos" en la Biblia son complementados y corregidos por lo que denomina "cualificadores" o "modificadores" y que hacen del discurso bíblico -en especial el de Jesús- un caso único. Estos cualificadores se expresan a través de modos de discurso que la Biblia atribuye a la forma de expre- 
sarse de Jesús, como son las parábolas, los proverbios y la proclamación escatológica; cada uno de estos modos es portador de una dinámica interna o ley denominadas "extravagancia" (muy propia de la metáfora), "hipérbole" y "paradoja", respectivamente.

Ricoeur llama ley de la trasgresión o lógica del escándalo a la dinámica interna de los modos de discurso bíblicos y de la forma de expresarse de Jesús, esta ley actúa sobre el lector desorientándolo para reorientarlo y abriendo en él lo extraordinario en lo ordinario, es un nuevo tipo de referente, un referente único entre los textos poéticos. Es por la trasgresión "que estas formas de discurso apuntan más allá de su significación inmediata hacia un Totalmente Otro" (1975b, 108).

De esta forma, desde el punto de vista hermenéutico, el referente Dios -o Reino de Dios en la predicación de Jesús- funciona como "referente-límite", es decir, un referente que limita las pretensiones que tiene el conocimiento objetivo de llegar a ser absoluto.

Sin embargo, desde la perspectiva de la apropiación existencial el referente del texto bíblico es la realidad humana en su totalidad. Es el encuentro con el conjunto de textos modelos y cualificadores, como expresiones-límite referidas a un referente-límite como es el Reino de Dios, el que abre la experiencia humana hacia lo que se podría llamar "experiencias-límite". Para Ricoeur el lenguaje religioso usa las expresiones-límite para abrir la experiencia humana misma, para hacerla estallar hacia experiencias que son, también, experiencias-límite (cf. 1974a, 89).

Por otro lado, no podemos olvidar que la vida ordinaria del ser humano está atravesada por experiencias de ruptura que contienen una fuerte capacidad de reorientar la vida, como son las experiencias de muerte, de sufrimiento, de culpa, o las experiencias culminantes de creación y alegría. Es por ello que podemos afirmar que el lenguaje religioso toca muy profundamente la experiencia humana porque esta es potencialmente religiosa.

Se produce, en este sentido, un nuevo diálogo. El mundo del texto bíblico apunta a la reorientación de la existencia humana abriéndola a experiencias límite. Pero, a su vez, las mismas experiencias de ruptura o culminantes, propias de la existencia humana, encuentran su sentido en el mundo propuesto por el texto bíblico, en lo dicho en el texto.

La experiencia humana tiene una dimensión potencialmente religiosa que se actualiza en el encuentro con el lenguaje religioso que, a su vez, proyecta su visión radical de la existencia. Aquí nos resuena una afirmación de Ricoeur: que "la fe es la actitud de quien acepta ser interpretado al mismo tiempo que él o ella interpreta el mundo del texto" $(1974 b, 46)$. Es esa actitud la que expresa la potencial religiosidad de la experiencia humana que, al ser interpretada por el mundo del texto se abre a la fe propiamente religiosa. Pero es tal la particularidad de ese mundo abierto por el lenguaje religioso-bíblico que toda la interpretación termina siendo excedida en su origen y límite por la fe que es abierta, por el mundo de Dios, por la trasgresión de todo lo que se había percibido como posible en la propia existencia, por la apertura de lo extraordinario en lo ordinario, por la proposición de un mundo Totalmente Otro en el que es posible habitar.

Para Ricoeur la fe cristiana, la fe bíblica, pasa necesariamente por el momento hermenéutico, por la interpretación, pero no para quedarse ahí, sino para abrirse a 
recibir el mundo de Dios propuesto por el texto bíblico y que lo excede por todas partes. Creer es dejarse interpretar y atreverse a habitar ese mundo nuevo, desear configurar la propia vida con la propuesta del Reino. No se puede creer en el Dios de Jesucristo sin dejarse interpelar y transformar por su Palabra.

Finalmente, podemos decir que ese mundo totalmente otro abierto por el texto bíblico y en el que es posible habitar, no es solo una creación del lenguaje y del pensamiento ni tampoco un asunto privado entre el creyente y Dios, sino que refiere a una praxis política transformadora del mundo (cf. 1977a, 122). De ahí surge la dimensión transgresora de la fe que impulsa a la recreación constante del mundo y de la realidad.

\section{RESUMEN}

A partir de la lectura serena de algunos escritos de Paul Ricoeur relacionados con la hermenéutica teológica, el artículo Interpretación y fe: una breve presentación de la hermenéutica teológica de Paul Ricoeur, es un intento por responder a las preguntas: ¿Cómo concibió la fe Paul Ricoeur desde su pensamiento hermenéutico? y ¿qué relación tiene la filosofía hermenéutica con la experiencia de la fe bíblica?.

Para Ricoeur la fe cristiana, la fe bíblica, pasa necesariamente por el momento hermenéutico, por la interpretación, pero no para quedarse ahí, sino para abrirse a recibir el mundo de Dios propuesto por el texto bíblico y que lo excede por todas partes. Creer es dejarse interpretar y atreverse a habitar ese mundo nuevo, desear configurar la propia vida con la propuesta del Reino. No se puede creer en el Dios de Jesucristo sin dejarse interpelar y transformar por su Palabra.

\section{ABSTRACT}

From the starting point of a considered review of some writings of Paul Ricoeur related to theological hermeneutics, the article Interpretation and Faith: a Brief Presentation of the Theological Hermeneutics of Paul Ricoeur is an attempt to respond to the following questions: How did Paul Ricoeur understand faith from his hermeneutical thought? What relation does philosophical hermeneutics have with the experience of biblical faith?

For Ricoeur, Christian faith-biblical faith-passes necessarily through the hermeneutic moment by interpretation, but not in order to remain there. Rather, it opens itself to receive the world of God proposed by the biblical text and that exceeds it everywhere. To believe is to allow oneself to interpret and dare to live that new world, to wish to configure one's own life with the proposal of the Reign of God. One cannot believe in the God of Jesus Christ without letting oneself be addressed and transformed by his Word.

\section{BIBLIOGRAFÍA}

1967: Paul RICOEUR, “Bultmann y Ebeling: Desmitologización y reinterpretación actual del mensaje cristiano”, en "El lenguaje de la fe", Buenos Aires, 1978, pp. 101-140.

1968a: Paul RICOEUR, “Lenguaje y teología de la palabra”, en "El lenguaje de la fe”, Buenos Aires, 1978, pp. 141-161. 
1968b: Paul RICOEUR, "Preface to Bultmann", en "Essays on Biblical Interpretation”, USA, 1979?, pp. 49-72.

1972: Paul RICOEUR, "La hermenéutica del testimonio", en "Fe y filosofía, problemas del lenguaje religioso", Buenos Aires, 1994, pp. 125-157.

1974a: Paul RICOEUR, "Manifestación y proclamación", en "Fe y filosofía, problemas del lenguaje religioso", Buenos Aires, 1994, pp. 73-98.

1974b: Paul RICOEUR, "Philosophy and religious language", en "Figuring the sacred, religion, narrative and imagination”, USA, 1995, pp. 35-47.

1975a: Paul RICOEUR, "La filosofía y la especificidad del lenguaje religioso", en "Fe y filosofía, problemas del lenguaje religioso", Buenos Aires, 1994, pp. 55-71.

1975b: Paul RICOEUR, "Biblical Hermeneutics", en Semeia, 4, 1975, pp. 27-147.

1975c: Paul RICOEUR, "La función hermenéutica de la distanciación”, en "Del texto a la acción”, París, 1986, pp. 245-261.

1975d: Paul RICOEUR, "Hermenéutica filosófica y hermenéutica bíblica", en "Del texto a la acción”, París, 1986, pp. 263-277.

1977a: Paul RICOEUR, "Nombrar a Dios", en "Fe y filosofía, problemas del lenguaje religioso", Buenos Aires, 1994, pp. 99-123.

1977b: Paul RICOEUR, "Hermenéutica de la idea de la revelación”, en "Fe y filosofía, problemas del lenguaje religioso", Buenos Aires, 1994, pp. 159-198.

1981: Paul RICOEUR, "The Bible and the imagination", en "Figuring the sacred, religion, narrative and imagination", USA, 1995, pp. 144-166.

1989: Paul RICOEUR, "Pastoral praxeology, hermeneutics, and identity", en "Figuring the sacred, religion, narrative and imagination”, USA, 1995, pp. 303-314.

1990: Paul RICOEUR, "El carácter hermenéutico común a la fe bíblica y a la filosofía”, en "Fe y filosofía, problemas del lenguaje religioso", Buenos Aires, 1994, pp. 221-229. 
